\title{
O choque nos preços das commodities e a economia brasileira nos anos 2000
}

\author{
Commodity prices shocks and the \\ Brazilian economy in the 2000s
}

\author{
MARCOS TADEU CAPUTI LÉLIS* \\ ANDRÉ MOREIRA CUNHA**,+ \\ PRISCILA LINCK***,
}

\begin{abstract}
RESUMO: O presente trabalho avalia os impactos macroeconômicos da queda nos preços das commodities na economia brasileira ao longo dos anos 2000. Por meio da aplicação de dois métodos estatísticos complementares — os modelos Markov Switching Dynamic Regression e Vetoriais Autorregressivos (VAR) - foi possível estimar que 1/3 da desaceleração econômica pós-2014 esteve associada à mudança no regime de preços das commodities. PALAVRAS-CHAVE: Preços das commodities; ciclos econômicos; economia brasileira.
\end{abstract}

ABSTRACT: This paper evaluates how falling commodity prices affected the Brazilian economy during the 2000s. In order to fulfill this objective two different statistical methods were used, the Markov Switching Dynamic Regression model with structural component and the Vector Autoregression (VAR) model. With respect to the level of activities, it was found that about $1 / 3$ of the economic slowdown post 2014 could be attributed to the change in the commodities prices regime.

KEYWORDS: Commodities prices; business cycles; Brazilian economy.

JEL Classification: O11; F44; E32; F63.

\footnotetext{
*Professor do Programa de Pós-Graduação em Economia da Unisinos, São Leopoldo/RS, Brasil. E-mail: mcaputi@uol.com.br. Orcid: https://orcid.org/ 0000-0001-7465-8049.

**Professor Associado do Departamento de Economia e Relações Internacionais da Universidade Federal do Rio Grande do Sul - UFRGS, Porto Alegre/RS, Brasil. E-mail: andre.cunha@ufrgs.br. Orcid: https://orcid.org/0000-0002-3746-5974.

+Pesquisador do CNPq.

***Coordenadora de Inteligência de Mercado da Abicalçados, Novo Hamburgo/RS, Brasil. E-mail: priscila.linck@hotmail.com. Orcid: https://orcid.org/0000-0001-6954-205X.

${ }^{\mathrm{x}}$ Economista pela Unisinos. Submetido: 31/Julho/2018; Aprovado: 9/Janeiro/2019.
} 


\section{INTRODUÇÃO}

Uma tempestade perfeita atingiu o Brasil em 2014. No último trimestre do ano, o que era uma desaceleração econômica se transformou em uma das maiores recessões da história republicana. A inflação voltou a estar em dois dígitos antes de retomar uma trajetória convergente com a tendência prévia, o desemprego ultrapassou o patamar de $13 \%$, reverteu-se a vitalidade do tecido social observada durante mais de uma década e os resultados fiscais se deterioraram velozmente. Em paralelo, a crise política generalizada, da qual o segundo processo de impeachment do período da redemocratização foi um episódio marcante, lançou sombras sobre a higidez das instituições.

Não seria, portanto, um exagero sugerir que o país adentrou no que aqui chamamos de a "Grande Reversão". Essa tem múltiplas dimensões, das quais duas merecem destaque: no plano político, o ciclo da redemocratização sob a égide da Constituição de 1988 experimentou o seu mais intenso tensionamento, multiplicando-se as vozes contrárias aos avanços sociais e institucionais dos últimos trinta anos (Singer, 2018; Carvalho, 2018 ${ }^{1}$; no econômico, entrou em colapso o processo de aceleração no crescimento verificado entre 2004 e 2010 (ou 2013), quando as taxas de variação da renda praticamente dobraram ante aquelas observadas no quarto de século que se seguiu à crise da dívida externa ${ }^{2}$. Tal período de maior dinamismo veio acompanhado de relativa estabilidade macroeconômica, redução da desigualdade na distribuição da renda, queda da pobreza e mobilidade social ascendente para parcelas importantes da população. O contraste entre o "antes" e o "depois" de tal reversão e a profundidade da crise que se inaugura em 2014 fizeram com que o debate econômico recente tenha se concentrado nas razões para tal colapso. Em termos gerais, os argumentos se diferenciam em torno da importância relativa dada aos determinantes domésticos e externos, estruturais e conjunturais, bem das suas interações, tanto para explicar a aceleração, quanto a crise que se segue. Adicionalmente, enfatiza-se a questão do papel do Estado na economia brasileira (Bonelli e Veloso, 2016; Pereira e Mattei, 2016; Arestis et al., 2017).

Uma linha de raciocínio influente, aqui chamada de convencional, sugere que o advento do Plano Real e a introdução de reformas de caráter liberal (abertura financeira e comercial; privatizações; desregulamentação etc.) conformaram os alicerces que teriam permitido o país deixar para trás o "inflacionismo", vale dizer, um padrão de ativismo estatal que distorceria preços e incentivos diversos com efei-

\footnotetext{
${ }^{1} \mathrm{O}$ argumento-padrão é que a Constituição de 1988 introduziu direitos sociais incapazes de serem cobertos pelo orçamento público, o que se traduziria, mais cedo ou mais tarde, em crise fiscal aguda. A solução, portanto, seria reduzir o gasto social e, em paralelo, a carga tributária (Almeida Jr. et al., 2015). Para uma crítica a essa perspectiva e uma análise da situação fiscal ver Gobetti e Orair (2017).

${ }^{2}$ Entre 1981 e 2017, as taxas média e mediana de crescimento do PIB brasileiro foram de, respectivamente, $2,2 \%$ a.a. e 3,0\% a.a.; no período $2004-2010$, a média e a mediana foram de $4,5 \%$ a.a e $5,1 \%$ a.a. Ampliando o horizonte temporal, de 2004 a 2013, a média e a mediana atingem 4,0\% a.a. Estimativas com base nos dados do IMF (2018).
} 
tos negativos sobre o nível de atividades e a inflação (Bacha e Bonelli, 2005; Franco, 2005). Nem mesmo a chegada à presidência de segmentos críticos daqueles pilares, a partir da eleição do presidente Luiz Inácio Lula da Silva (2003-2010), colocou em xeque o novo consenso. Isso porque, o primeiro governo Lula teria "rompido com a ruptura", assumido o tripé macroeconômico e introduzido reformas microeconômicas que modernizaram a intermediação financeira, dentre outras áreas (Giambiagi, 2011; Lisboa e Latiff, 2013). Com isso, preservou-se a estabilidade herdada da gestão Cardoso (1995-2002) e, beneficiado por essa e pelo choque externo favorável da alta nos preços das commodities, a nova administração simplesmente colheu o que não havia semeado: a aceleração do crescimento. Por sua vez, o renovado vigor da economia abriu espaço fiscal para a adoção de políticas sociais mais robustas (Cardoso et al., 2018).

Assim, o crescimento da renda, a sensível melhoria nas condições do mercado de trabalho, a queda na pobreza e na miséria, a ascensão da "nova classe média" (Neri, 2011), dentre outros fenômenos, seriam, em última instância, o resultado da combinação de "continuísmo" e "sorte". Todavia, segue o raciocínio, com o advento da crise financeira global de 2007-2008 voltou o ativismo estatal, aprofundado na gestão da presidente Dilma Rousseff (2011-2016). A crise fiscal se agravou, ainda que mascarada pela "contabilidade criativa". Isso teria produzido um ambiente de insegurança que reduziu investimentos e, com isso, o crescimento econômico. A crise política no segundo mandato Dilma, a despeito da sua guinada conservadora sob o comando do ministro da Fazenda Joaquim Levy, só revelou o caráter insustentável do "populismo" ou do "desenvolvimentismo" em sua nova encarnação (Lisboa e Latiff, 2013; Barbosa Filho e Pessoa, 2014; Carrasco et al., 2014; Cardoso et al., 2018).

Essa narrativa tornou-se dominante nos meios de comunicação tradicionais, nas análises de assessorias econômicas de instituições financeiras e empresarias e em parte da academia. Adicionalmente, sedimentou as bases para as medidas de austeridade fiscal adotadas já no segundo mandato da presidente Dilma e, com intensidade redobrada, no governo Temer (2016-2018). Esse não foi capaz de relançar o país em uma trajetória de crescimento robusta e estável o que, para os proponentes dessa corrente explicativa, só reafirmaria que a crise seria produto de uma crise fiscal estrutural, mascarada pela "contabilidade criativa" dos governos liderados pelo Partido dos Trabalhadores, associada ao caráter desorganizador do intervencionismo pós-2008. Todavia, parece haver uma relação pouco clara entre a contundência retórica dessa literatura e a sua capacidade de oferecer evidências robustas sobre os elos de causalidade e de importância relativa dos distintos determinantes da crise. Ela parece atribuir efeitos assimétricos ao ambiente externo na determinação do desempenho macroeconômico doméstico, onde a desaceleração no ritmo de crescimento seria fruto das decisões domésticas de política econômica, ao passo que a aceleração se originaria nos choques exógenos de preços (Borges, 2016a, 2016b; Cardoso, 2018).

O presente trabalho parte de uma perspectiva alternativa e que emerge da crítica de institucionalistas, keynesianos e estruturalistas ao padrão de desenvolvimento do país da era da globalização (Marconi et al., 2016; Bresser-Pereira et al., 2016; Fer- 
rari Filho e Fonseca, 2015; Hiratuka e Sarti, 2017; Fonseca et al., 2018). Assume-se que a economia brasileira atravessa um longo processo de semiestagnação, que veio associado à perda de densidade e de complexidade de sua estrutura produtiva e de comércio exterior. A elevada abertura financeira e a especialização regressiva ${ }^{3}$, derivada da combinação entre a desindustrialização e a maior dependência da produção e venda externa de recursos naturais, tornou o país mais suscetível aos ciclos financeiros e aos ciclos de preços de commodities ${ }^{4}$. Assim, a compreensão da dinâmica econômica brasileira deve passar pelo reconhecimento da importância dos aspectos estruturais e conjunturais que a condicionam, tanto domésticos, quanto externos.

Com isso, seu objetivo principal é o de identificar os efeitos dos choques negativos dos preços das commodities entre os anos de 2002 e 2016 em três agregados macroeconômicos do Brasil: (a) nível de atividade; (b) taxa de câmbio nominal; e (c) inflação. Busca-se contribuir com o debate previamente mencionado ao prover evidências sobre a relação entre os ciclos de preços das commodities e a recessão observada entre 2014 e 2016. Para tanto, foram utilizados dois métodos estatísticos diferentes o que, até onde é do nosso conhecimento, revela-se como estratégia ainda não empregada na literatura prévia. O primeiro envolve a aplicação do modelo Markov Switching Dynamic Regression com componente estrutural $\left(\mathrm{MScomp}\left(\mathrm{S}^{\mathrm{m}}, \mathrm{S}^{\mathrm{v}}\right)-\mathrm{DR}(\mathrm{p})\right)$, que permitiu identificar dois ciclos de baixa nos preços das commodities: um entre 2008 e 2009; e outro entre 2014 e 2016. Com o recorte temporal estabelecido, lançou-se mão da metodologia de modelos Vetoriais Autorregressivos (VAR) para estimar os efeitos dinâmicos da baixa naqueles preços sobre o nível de atividade e os preços macroeconômicos. Verificou-se que: (i) o choque associado à crise financeira global não gerou impactos duradouros sobre as nossas variáveis de interesse; e (ii) a mudança no regime de preços das commodities depois de 2014 produziu efeitos perenes, que em seu auge corresponderam a $1 / 3$ da desaceleração econômica.

Tal resultado pode ser uma indicação indireta de que a especialização regressiva da economia brasileira contribui não somente para que o nível médio de crescimento tenha se reduzido nas últimas quatro décadas, como sua dinâmica tenha se tornado mais volátil e suscetível aos impulsos externos oriundos, dentre outros, das variações abruptas dos preços de recursos naturais. Além desta introdução, o trabalho está estruturado em mais três seções. Na sequência, faz-se breve revisão da literatura sobre o desempenho recente da economia brasileira. Os resultados dos exercícios realizados são apresentados na seção seguinte e, após, as considerações finais.

\footnotetext{
${ }^{3}$ Conforme argumentação seminal de Coutinho (1997). Trata-se da perda de densidade e de complexidade da estrutura produtiva e de comércio exterior. Argumentos e evidências recentes podem ser encontrados em Marconi et al. (2016) e Hiratuka e Sarti (2017).

${ }^{4}$ Esses historicamente afetam os países emergentes e em desenvolvimento, como sugerem as interpretações alternativas (Tavares, 1972; Belluzo e Almeida, 2002; Bresser-Pereira, 2016). A literatura convencional, especialmente a internacional, também reconhece a importância da dinâmica cíclica, mas só recentemente passou a enfatizar a dimensão dos ciclos financeiros (Reinhart, Reinhart e Trebesch, 2016; Alberola-Ila, 2016; De La Torre et al., 2016).
} 


\section{UM OLHAR PANORÂMICO SOBRE A “GRANDE REVERSÃO”}

Ao longo do século XX, pelo menos até a eclosão da crise da dívida externa, no começo dos anos 1980, a economia brasileira caracterizou-se pelo elevado dinamismo, com taxas de crescimento da renda superiores à média mundial (Figura 1) e que excediam àquelas observadas nas principais economias avançadas. A partir dos anos 1930, e com maior intensidade entre os anos 1950 e 1980, a combinação de extensa industrialização e rápida urbanização modificaram, de forma profunda, a estrutura socioeconômica do país (Belluzzo e Almeida, 2002; Bresser-Pereira, 2016).

Para se colocar tal transformação em perspectiva, basta lembrar que, no começo dos anos 1980, a produção industrial brasileira era a oitava maior do planeta, superando a produção conjunta das principais nações asiáticas em desenvolvimento. Naquele momento, o valor adicionado pelo setor manufatureiro do Brasil representava $2,7 \%$ do total mundial; e as exportações brasileiras de bens industriais atingiam $1,2 \%$ das vendas globais. $\mathrm{Na}$ década de 2010 , tais proporções se reduziram para, respectivamente, $1,5 \%$ a $2,0 \%$ e $0,7 \%$. Ainda ao se comparar o auge da industrialização com o período contemporâneo, cabe recordar que a renda gerada na indústria oscilava entre $25 \%$ e $30 \%$ do PIB nacional na década de 1970 e começo dos anos 1980; de lá para cá, o recuo tem sido constante, ao ponto de tal proporção situar-se entre 10\% e 15\% nos anos 2000 (Palma, 2012; Unido, 2015; Unctad, 2016).

Figura 1: Crescimento da Economia Brasileira, 1901-2017

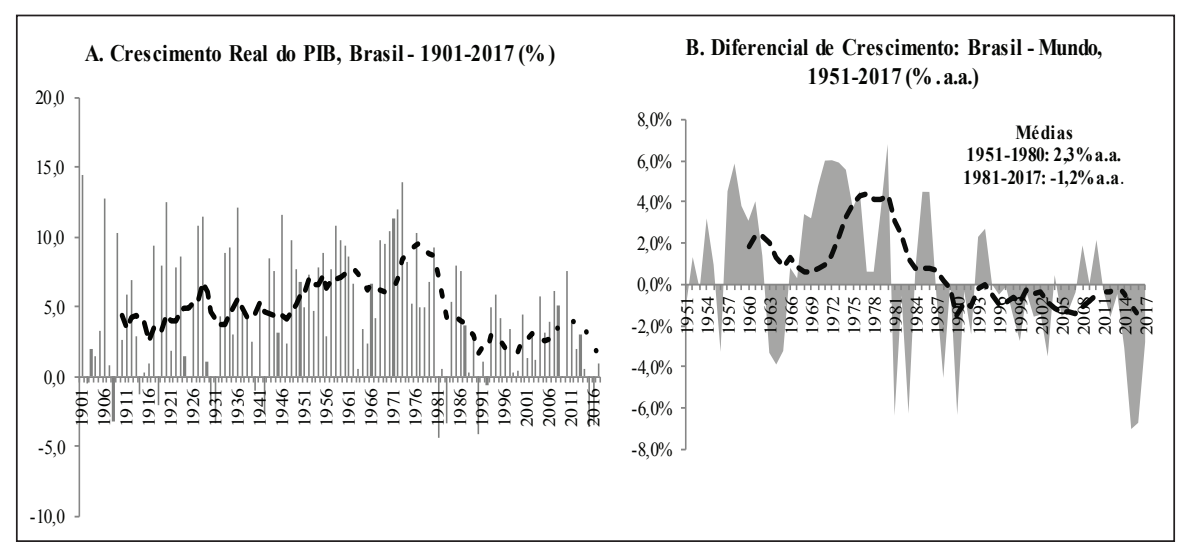

Fonte: IMF (2018), Ipeadata e Angus Maddison Historical Statistics. A linha pontilhada reporta a média móvel de 10 anos.

A literatura especializada tem buscado explicar as razões para o colapso do crescimento da economia brasileira (Bacha e Bonelli, 2015; Palma, 2012). A partir de diferentes perspectivas teóricas há pelo menos um ponto de convergência, que é a constatação de um problema central, qual seja: a perda no vigor dos investimentos e os incrementos modestos da produtividade. Todavia, tal ponto de parti- 
da encontra caminhos explicativos distintos. Por um lado, a visão aqui denominada de "convencional" enfatiza os problemas derivados da intervenção estatal durante o período desenvolvimentista, entre os anos 1950 e 1980, e novamente nos anos 2000, especialmente: (i) as distorções de preços e, por decorrência, as decisões ineficientes na alocação intertemporal dos recursos, e (ii) o ambiente institucional instável e hostil aos investidores privados (Franco, 2004; Bacha e Bonelli, 2005; Lisboa e Latif, 2013; Barbosa Filho e Pessoa, 2014).

As interpretações alternativas criticam o padrão de inserção do Brasil na economia internacional, o viés deflacionista das políticas macroeconômicas e os problemas associados à especialização regressiva e ao processo de desindustrialização. Argumenta-se que nas últimas três ou quatro décadas, período que coincide com o aprofundamento da globalização com dominância financeira, o país adotou estratégias equivocadas de inserção externa. A excessiva abertura financeira teria produzido volatilidade excessiva nos preços macroeconômicos fundamentais e crises recorrentes, cujos efeitos se fizeram sentir nos desequilíbrios patrimoniais dos setores privados e público e, com isso, no estreitamento do horizonte temporal nas decisões de reprodução da riqueza. Ademais, as reformas neoliberais teriam diminuído a capacidade estatal em realizar investimentos capazes de sustentar horizontes mais largos de expansão do conjunto da economia. A estes problemas se somariam características mais profundas da sociedade, como a postura rentista e predatória da sua elite (Belluzzo e Almeida, 2002; Arestis e Saad-Filho, 2008; Palma, 2012; Bresser-Pereira, 2016). Ademais, a perda de dinamismo da indústria de transformação seria peça central na explicação do baixo crescimento.

O presente trabalho alinha-se à perspectiva orientada pelas tradições estruturalista e keynesiana, especialmente quando inspiradas na perspectiva kaldoriana, que enfatiza a importância da diversificação das estruturas de produção e exportação, com ênfase para o papel da indústria de transformação como motor do crescimento (Palma, 2012; Bresser-Pereira et al., 2016; Ferrari Filho e Fonseca, 2015; Hiratuka e Sarti, 2017; Fonseca et al., 2018). Assume-se, portanto, que a especialização regressiva da economia brasileira e o seu padrão de abertura financeira podem ter tornado o país mais vulnerável às variações abruptas dos preços dos recursos naturais e aos choques financeiros. Por isso mesmo observa-se que, desde o advento da crise da dívida externa, o Brasil cresceu sistematicamente abaixo da média mundial, em cerca de um ponto percentual por ano (Figura 1), abaixo da média das economias emergentes e em desenvolvimento e, em alguns períodos, abaixo da média latino-americana. Dado esse processo de decadência relativa, parte dos anos 2000 foram atípicos porque caracterizados por um processo de convergência entre aceleração no crescimento, melhor distribuição da renda, redução da pobreza e maior resiliência macroeconômica, que é a capacidade de absorver choques externos e que foi manifesta, de forma clara, quando da eclosão da crise financeira global de 2007-2009 (CFG).

Em parte, tais elementos foram impulsionados pelo contexto global de ascensão das potências emergentes, particularmente da China, em um momento em que as economias avançadas, lideradas pelos EUA, mantinham processos domésticos 
de expansão do consumo a partir da forte elevação no endividamento das famílias, o que permitiu a constituição de um ciclo de elevação dos preços internacionais das commodities com moderação na evolução dos preços dos bens industriais. Tal choque favorável nos termos de intercâmbio contribuiu para a ampliação dos investimentos nos países produtores e exportadores de recursos naturais, bem como reduziu as restrições financeiras, fiscal e externa. A apreciação do Real derivada dos influxos de divisas também permitiu a ampliação do poder de compra dos salários. No plano interno, iniciativas redistributivas, como a recuperação no poder de compra do salário mínimo, as políticas de transferência de renda para as camadas mais pobres da população e a expansão na oferta de crédito também desempenharam um papel positivo. É neste cenário que se dá a retomada do ativismo estatal no Brasil, que antecedeu à eclosão da CFG, ganhando força por conta desta, ainda que com um formato mais associado às típicas políticas contracíclicas voltadas à estabilização da demanda no curto prazo (Ferrari Filho e Fonseca, 2015; Arestis et al., 2017; Fonseca et al., 2018).

Após a CFG, o governo brasileiro seguiu a tendência internacional de adoção de estímulos monetários, creditícios e fiscais contundentes. Retrospectivamente, pode-se afirmar que tais iniciativas garantiram o amortecimento dos seus impactos e em 2009, quando o PIB experimentou contração de $0,3 \%$, possibilitando uma recuperação vigorosa já em 2010, com um crescimento de 7,5\%. Em 2011, o governo central conduziu um aperto fiscal, que veio se somar à retomada da política monetária restritiva. Isto porque havia sinais de que a aceleração do crescimento vinha acompanhada de pressões inflacionárias significativas. O ambiente internacional foi-se tornando cada vez menos favorável a partir de 2011, pois emerge um quadro de: (i) crescente instabilidade nos mercados financeiros, devido aos problemas de endividamento das economias europeias e as fragilidades financeira disseminadas em diversos países; (ii) baixo crescimento do conjunto das economias maduras, particularmente os EUA, agravada pelos efeitos da crescente tensão política do congresso estadunidense sobre a situação fiscal do país; e (iii) desaceleração no crescimento das principais economias emergentes, particularmente a China, o que comprometeu o bom desempenho do comércio mundial de commodities - minerais, energéticas e alimentos.

Neste novo período, verificou-se, por parte do governo federal, a renovação, com ainda maior intensidade, da aposta nos estímulos fiscais, por meio, principalmente, de desonerações tributárias diversas, e de apoio aos bancos públicos, como fontes estratégicas para a sustentação do crédito para investimentos de longo prazo, o que não garantiu a manutenção de taxas robustas de crescimento. Houve, também, um afrouxamento da política monetária, que permitiu aliviar as pressões de apreciação do Reals. Se o segundo pilar se mostrou efetivo, na medida em que

\footnotetext{
${ }^{5}$ Entre agosto de 2011 e março de 2013 o Copom-BCB reduziu a taxa básica de juros - SELIC - de $12,50 \%$ a.a para $7,25 \%$ a.a. Nesse mesmo período a cotação média do dólar passou da faixa de $\mathrm{R} \$$ 1,60 para $\mathrm{R} \$ 2,20$.
} 
o crédito privado deixou de irrigar a economia a partir da crise de 2008, cabendo ao crédito público sustentar os níveis já medíocres da formação bruta de capital, o primeiro pilar parece não ter funcionado adequadamente. A partir de meados de 2013 começou a se caracterizar uma reversão importante, quando o baixo dinamismo em termos de expansão do nível de atividade passou a ser acompanhado pela deterioração nos principais fundamentos macroeconômicos (Arestis et al., 2017). No plano externo, ficou para trás a bonança do período de choque favorável nos termos de intercâmbio. A combinação entre vários anos em que a demanda doméstica crescia acima da capacidade produtiva local, com queda nos preços internacionais dos recursos naturais e, até meados de 2013, um Real forte, se traduziu em déficits em conta-corrente entre $3 \%$ e $4 \%$ do PIB. As pressões inflacionárias foram sendo contidas pela política fiscal, como nos casos emblemáticos da energia elétrica e dos combustíveis. A primeira onda de protestos populares, em junho de 2013, e o ambiente eleitoral acirrado, em 2014, induziram os governos central e locais (estados e municípios) a ampliar os estímulos fiscais para além das respectivas capacidades de arrecadação em meio às trajetórias declinantes de crescimento da renda (Carvalho, 2018; Singer, 2018).

Em 2015 e 2016, o produto entrou em queda livre, com variação negativa da ordem de $-3,5 \%$ ao ano. A inflação chegou a oscilar na faixa de $10 \%$, a taxa de desemprego e o resultado fiscal também se aproximam rapidamente dos dois dígitos. Somente as contas externas deram sinais de melhora, ainda que por razões menos virtuosas: o déficit em conta-corrente diminuiu em virtude da alta no valor do dólar e da queda da demanda doméstica por bens e serviços importados. A piora na economia associou-se com a crise política aberta, quando importantes lideranças políticas e empresariais passaram a ser alvo de investigações por parte das operações policiais e judiciais, que culminaram com o segundo impeachment presidencial do período pós-redemocratização (Cardoso et al., 2018; Carvalho, 2018; Singer, 2018).

Assim, após décadas de modernização produtiva, fruto de mudanças estruturais que ampliaram a sua produtividade, o Brasil experimentou um longo processo de especialização regressiva, que se inaugurou com a crise da dívida externa, no começo dos anos 1980. Nas duas décadas subsequentes, a instabilidade macroeconômica e o baixo crescimento foram a regra e as políticas de Estado priorizaram a estabilização inflacionária e as reformas pró-mercado. Nos anos 2000, voltaram a aceleração do crescimento com distribuição de renda e o ativismo estatal, o que não evitou a persistência do movimento mais geral de perda de eficiência do sistema produtivo.

É importante destacar que a presente síntese não explora todas as nuances da rica e controversa literatura sobre os determinantes da perda de dinamismo da economia brasileira, tanto no que se refere aos seus determinantes estruturais e conjunturais quanto exógenos, usualmente associados ao comportamento da economia global, e endógenos, particularmente aqueles derivados das decisões de 
política econômica ${ }^{6}$. No que concerne ao debate específico dos anos 2000, particularmente para a aceleração no ritmo de crescimento antes de 2008 e a crise pós-2014, os choques exógenos nos preços de commodities e financeiros seriam considerados centrais para explicar o desempenho das economias emergentes, em geral, e do Brasil em particular, conforme sugerem, dentre outros, De La Torre (2016), Reinhart et al. (2016), Alberola-Ila (2016) e Borges (2016a, 2016b). A combinação entre maior liquidez financeira e preços elevados de commodities teriam diminuído as restrições fiscais e de financiamento externo, permitindo a expansão dos gastos domésticos. Já a reversão desses fatores teria precipitado a crise recente. A dimensão associada ao choque de preços de commodities será explorada na próxima seção, o que se constitui na contribuição principal do artigo.

\section{OS CHOQUES NEGATIVOS DOS PREÇOS DAS COMMODITIES E A DINÂMICA MACROECONÔMICA DOS ANOS 2000}

A estratégia empírica utilizada neste trabalho combina dois momentos. Inicialmente, aplica-se o modelo Markov Switching com componente estrutural para identificar os regimes de alta e de baixa nos preços das commodities. Com isso, tem-se a demarcação do recorte temporal para os ciclos de baixa, o que permite estimar os efeitos dinâmicos dos choques negativos daqueles preços por meio de Modelos Vetoriais Autorregressivos (VAR). Foram utilizadas seis séries temporais com uma periodicidade mensal, todas medidas em número índice (base $100=01 / 2002$ ): três proxies para o nível de atividade - produção física da indústria de transformação (IND), produto interno bruto (GDP) e índice de atividade econômica do Banco Central do Brasil (IBC) -; a taxa de câmbio nominal (EX); a inflação, medida pelo IPCA (IN); e

\footnotetext{
${ }^{6}$ Do ponto de vista das explicações para a trajetória de longo prazo da economia, os trabalhos inspirados em modelos neoclássicos de crescimento e em abordagens alinhadas à nova economia institucional (NEI) consideram que os problemas fundamentais da economia brasileira se originam no excesso de intervenção do Estado (Bonelli e Bacha, 2005). Este produziria, no plano microeconômico, distorções alocativas e, com isso, insuficiente acumulação de capital físico e humano; e, no plano macroeconômico, desequilíbrios diversos, especialmente nas contas públicas. Tais aspectos teriam sido potencializados no período pós-2008, como destacam Pessoa (2016), Matos (2016) e a maioria dos trabalhos reunidos por Bacha (2016) e Giambiagi e Almeida Jr. (2017). Alternativamente, interpretações críticas ao mainstream da Economia enfatizam os problemas derivados da combinação entre a perda de diversificação e de complexidade da estrutura produtiva, o padrão de inserção do Brasil na economia internacional e o viés deflacionista das políticas macroeconômicas (Marconi et al., 2016; Hiratuka e Sarti, 2017; Fonseca et al., 2018). Argumenta-se que no período de aprofundamento da globalização com dominância financeira, a partir dos anos 1980, o país adotou estratégias equivocadas de inserção externa e de gestão macroeconômica. A abertura financeira teria produzido volatilidade excessiva nos preços macroeconômicos fundamentais e crises recorrentes, cujos efeitos se fizeram sentir nos desequilíbrios patrimoniais dos setores privados e público e, com isso, no estreitamento do horizonte temporal nas decisões de reprodução da riqueza. Ademais, as reformas liberais e a manutenção do tripé macroeconômico - metas de inflação, câmbio flutuante e geração de superávits fiscais — teriam diminuído a capacidade estatal em realizar investimentos capazes de sustentar horizontes mais largos de expansão do conjunto da economia.
} 
índice de preços das commodities $(\mathrm{CO})^{7}$. No VAR, todas as séries passaram por um ajuste sazonal (método Census-X13 - Arima-X13) e foram definidas em logaritmo. Já para metodologia Markov Switching, o ajuste sazonal foi aplicado no próprio modelo, partindo da inserção de variáveis dummies sazonais, sendo utilizada a variável CO em número índice. Para o modelo Markov Switching o período analisado vai de janeiro/1995 até dezembro/2016; ao passo que para o modelo VAR foi de janeiro/2002 até dezembro/2016. Isso se deve aos resultados do primeiro e à disponibilidade limitada de dados para algumas séries utilizadas.

A Figura 2 mostra a evolução das nossas variáveis de interesse. Nota-se que a aceleração ritmo de expansão do nível de atividades, com as três proxies aqui utilizadas, esteve associada os movimentos de alta nos preços das commodities. Da mesma forma, a queda desses coincide com os momentos de perda de dinamismo. Tal fato estilizado é destacado na literatura, tanto keynesiana, quanto convencional (Prates, 2007; Barbosa Filho, 2015; Alberola-Ila, 2016; De La Torre et al., 2016).

Figura 2: Indicadores Macroeconômicos Selecionados, 2002-2016

(número índice e dados dessazonalizados)

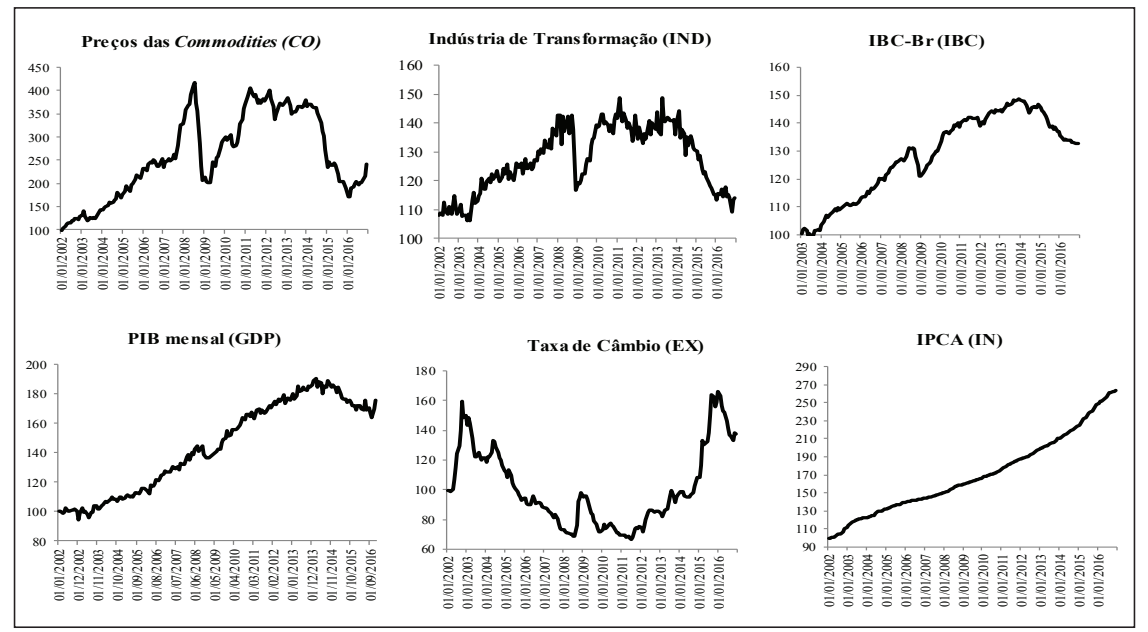

Fontes: IBGE, Banco Central do Brasil e FMI.

Seguindo a sugestão de Doornik (2012, 2013), aplicou-se um modelo markoviano dinâmico com componente estrutural ${ }^{8}$ para analisar os preços das commo-

\footnotetext{
${ }^{7}$ O IBGE é a fonte para a produção industrial e o IPCA; o Banco Central do Brasil é a origem para a estimativa do PIB mensal, o IBC-Br e a taxa nominal de câmbio (que está medida como BRL por USD, de modo que uma elevação no número índice representa a depreciação da moeda brasileira); e o Fundo Monetário Internacional é a fonte do índice das commodities, cuja elevação (queda) representa alta (baixa) de tais preços.

${ }^{8}$ A literatura sugere que tal opção é preferível ao Markov Switching Autoregressive (MS-AR), na medida em que o modelo MS-DR captura melhor situações onde alterações de regimes são mais acentuadas. Ver: Goldfeld e Quandt (1973), Lindegren (1978), Kim (1994), Hamilton (1990 e 1994) e Doornik (2013).
} 
dities (CO). Segundo o autor, as séries temporais que passam por período de "grande moderação" podem não apresentar regimes de média $(\mathrm{m})$ e variância $(\mathrm{v})$ coincidentes nos mesmos períodos. Nesse caso, a média da série pode flutuar mais rapidamente que a sua variância. Assim, trabalha-se com um $\mathrm{MScomp}(\mathrm{Sm}, \mathrm{Sv})$ -DR(p), onde "S" representa o número de regimes da média $(\mathrm{m})$ e da variância $(\mathrm{v})$ e "p" é o número de defasagem utilizada na regressão. Assim:

$$
y_{t}=r\left(S_{t}\right)+\sum_{i=1}^{p} \alpha_{i} \cdot y_{t-1}+\sum_{i=1}^{11} \gamma_{i} \cdot D U_{t}+u_{t}, \quad u_{t} \sim i . i . d .\left(0, \sigma^{2}\right)
$$

Onde: $y_{t}$ representa a variável que estabelece os regimes (neste caso de $\mathrm{CO}$ ); $D U_{t}$ constitui as dummies sazonais; $S_{t}$ é uma variável de estado que denota os regimes para média; e $u_{t}$ descreve os resíduos estimados, independente e identicamente distribuídos, com média zero e variância constante. Ao mesmo tempo, ao se caracterizar um modelo com quatro regimes, dois para média e dois para variância, chega-se às seguintes matrizes de probabilidade de transição:

\begin{tabular}{c|cc} 
& $S_{t}^{m}=0: \mu_{0}$ & $S_{t}^{m}=1: \mu_{1}$ \\
\hline$S_{t+1}^{m}=0: \mu_{0}$ & $p_{0 / 0}^{m}$ & $p_{0 / 1}^{m}$ \\
$S_{t+1}^{m}=1: \mu_{1}$ & $p_{1 / 0}^{m}$ & $p_{1 / 1}^{m}$ \\
& $S_{t}^{v}=0: \sigma_{0}$ & $S_{t}^{v}=1: \sigma_{1}$ \\
\hline$S_{t+1}^{v}=0: \sigma_{0}$ & $p_{0 / 0}^{v}$ & $p_{0 / 1}^{v}$ \\
$S_{t+1}^{v}=1: \sigma_{1}$ & $p_{1 / 0}^{v}$ & $p_{1 / 1}^{v}$
\end{tabular}

As matrizes caracterizam as probabilidades de transição (média e variância) entre os $\mathrm{S}$ regimes existentes no sistema, tal que a soma de cada coluna é igual a 1 . O elemento $p_{0 / 0}^{m}$ representa a probabilidade de transição da média do estado ou regime 0 , no período $t$, para o estado 0 , no período $t+1$; vale dizer, de permanecer no mesmo regime entre os tempos $t$ e $t+1$.

Isto posto, a aplicação do modelo Markov Switching para CO permitiu identificar uma estrutura MScomp(2,2)-DR(2) , conforme Tabela 1 (ver Anexo). Pelos parâmetros estimados, o Regime 0 é definido como de Alta e o Regime 1 é o de Baixa. As matrizes de probabilidade de transição da média e da variância estimada (ver Tabela 2, no Anexo) revelam um padrão robusto de estabilidade. Isto é, ao se posicionar no Regime de Alta (Regime 0), no tempo " $\mathrm{t}$ ", a probabilidade de permanecer nesse regime no tempo " $t+1$ " é de $97,826 \%$. Para a variância da série, a probabilidade de permanecer no regime de Alta entre o tempo " $t$ " e " $t+1$ " foi de $99,159 \%$.

\footnotetext{
${ }^{9}$ Os demais modelos estimados apresentam heterocedasticidade e/ou autocorrelação nos resíduos; ou, ainda, são inferiores nos critérios de Akaike (AIC) e Schwarz (SIC) na última estrutura estatística.
} 
$\mathrm{Na}$ sequência foram estimados os Regimes de Baixa e Alta da média e da variância da série CO (ver Tabela 3, no Anexo). Ao se observar a periodicidade dos regimes para média de CO, identificou-se período longo (159 meses) de Regime Baixo, ao qual seguem 38 meses de Regime Alto. Esse é interrompido com a crise Subprime, em 2008(8), ao qual seguem 7 meses de Regime de Baixa. O próximo Regime de Baixa cobre o período 2014(7) a 2016(12). Os regimes estimados para variância de $\mathrm{CO}$ apresentam diferentes periodicidades ante os regimes da média. Ressalte-se que a partir de 2002(11) até o final do período analisado (170 meses sem interrupção), há um Regime de Alta para variância. Isso nos permite sugerir que o ciclo de alta dos preços das commodities dos anos 2000 caracterizou-se por elevada volatilidade.

Com esses resultados, pode-se delinear o período de tempo e as dummies que serão introduzidas para estimar os efeitos dos multiplicadores dinâmicos no modelo VAR (Lütkepohl, 2006; Juselius, 2006; Enders, 2010). Esse cobriu os meses de janeiro de 2002 até dezembro de 2016, dada a disponibilidade dos dados, especialmente para as séries que representam o nível de atividade da economia brasileira ${ }^{10}$. O modelo VAR estimado está assim especificado:

$$
y_{t}=v+A_{1} \cdot y_{t-1}+\cdots+A_{p} \cdot y_{t-p}+B \cdot D U_{t}^{C O}+e_{t}, \quad e_{t} \sim i . i . d \cdot\left(0, \sigma^{2}\right)
$$

Onde: $y_{t}$ estabelece o vetor das variáveis utilizadas no modelo estimado; os elementos $A_{p}$ caracterizam as matrizes dos coeficientes estimados relacionados com as variáveis endógenas; $v$ é o vetor de intercepto; B é a matriz com os coeficientes estimados relativos às dummies dos regimes de baixa nos preços das commodities; $D U_{t}^{c o}$ especifica um vetor composto pelas variáveis dummies de controle dos regimes de baixa dos CO; e, por fim, $e_{t}$ indica o vetor dos resíduos estimados.

Para estimar o movimento de passagem de um Regime de Alta para um Regime de Baixa foram introduzidas duas dummies de Regime de Baixa nos preços das commodities: 2008(8) até 2009(2) - DU1 e 2014(7) até 2016(12) - DU2. Assim, a equação (3) está composta por um vetor de variáveis endógenas com as seguintes séries: IND, IN, EX e CO (VAR(IND)); GDP, IN, EX e CO (VAR(GDP)); IBC, IN, EX e CO (VAR(IBC). Com isso, são estimados três estruturas de modelo VAR para cada período, onde em cada uma delas se impõe um vetor de variáveis exógenas com duas dummies DU1 e DU2.

A construção de um modelo vetorial identifica, entre as variáveis endógenas do modelo, quais seriam mais endógenas, sendo o primeiro elemento do modelo VAR o último a reagir aos choques exógenos. É possível, com isso, estabelecer a hipótese sobre o processo de causação dos choques. Para os VAR's propostos a variável mais exógena será os $\mathrm{CO}$, sendo a mais endógena a respectiva proxy para o nível de atividade (IND, GDP ou IBC). Os testes de estacionariedade ${ }^{11}$, raiz unitá-

\footnotetext{
${ }^{10}$ Para o modelo do IBC-Br a periodicidade é de janeiro/2003 até dezembro/2016.

${ }^{11}$ Foram estimados os testes Dickey-Fuller ampliado (ADF), Kwiatkowski-Phillips-Schmidt-Shin (KPSS),
} 
ria e análise dos resíduos (ver Tabelas 4 e 5, e Gráfico 1A, no anexo) nos permitem utilizar um modelo VAR com as variáveis em primeira diferença ${ }^{12}$. Cada função impulso-resposta acumulada considera efeitos para vinte meses de duração. Os resultados estão nas figuras 3 e 4 que mostram, respectivamente, os efeitos dos dois Regimes de Baixa identificados: 2008(8) até 2009(02); e 2014(7) até 2016(12).

Para o primeiro período (Figura 3), ressalta-se que: (i) um choque negativo da mudança de regime dos preços das commodities (DU1) produziu efeitos negativos sobre o nível de atividades nos três modelos testados - IND, GDP ou IBC -; e (ii) os efeitos cumulativos dos choques se dissiparam para as três proxies.

Figura 3: Efeitos do Multiplicador Dinâmico Acumulado sobre as Variáveis do Modelo VAR(IND-10), VAR(GDP-14) e VAR(IBC-6) - Regime de Baixa 2008(8) até 2009(2) - DU1

Respostas no Nível de Atividade (IND, GDP e IBC)

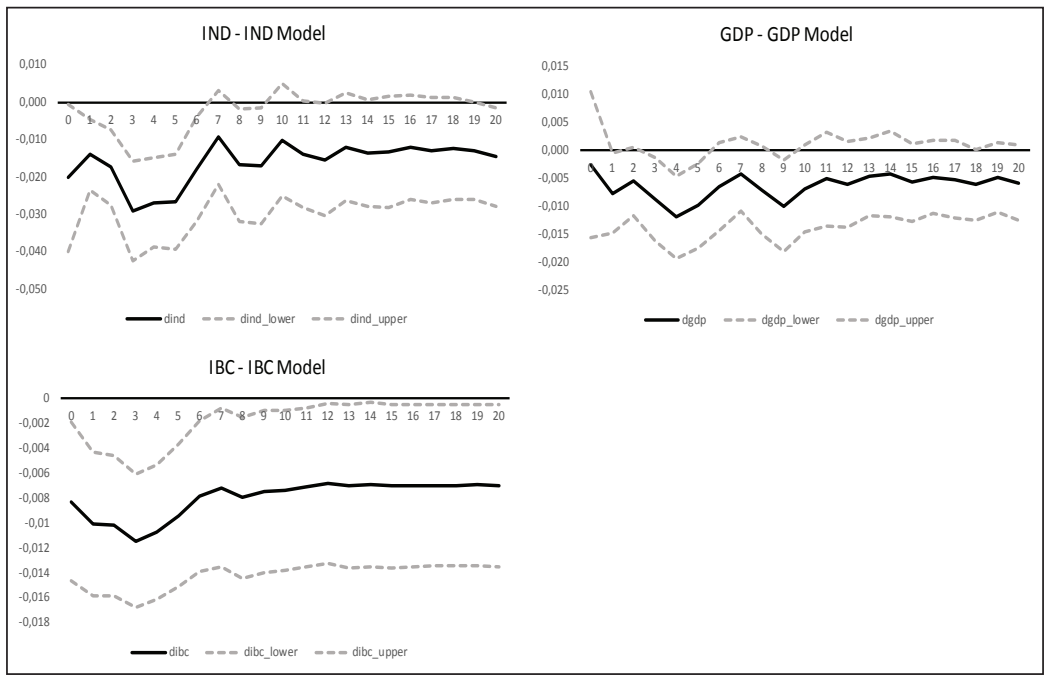

Fonte: Elaboração dos autores. Estatísticas estimadas pelo Software STATA 15.1.

A Figura 4 apresenta os efeitos dinâmicos acumulados do regime de baixa dos preços das commodities, entre 2014/07 até 2016/12 (DU2), nos agregados macroeconômicos selecionados da economia brasileira. Aqui os efeitos dos choques negativos nos preços das commodities mostram-se duradores.

ADF com quebra; Zivot-Andrews (ZA). Em todas as séries utilizadas, pelo menos três especificações foram I(1) com nível de significância de $5 \%$.

12 As defasagens dos modelos serão: VAR (IND-10); VAR(GDP-11); VAR(IBC-6). Todos os modelos apresentam um padrão estacionário. Foi aplicado um teste de ruído branco sobre os resíduos estimados ao quadrado de cada equação do VAR. 
Figura 4: Efeitos do Multiplicador Dinâmico Acumulado sobre as Variáveis do Modelo VAR(IND-10), VAR(GDP-14) e VAR(IBC-6) - Regime de Baixa 2014(7) até 2016(12) - DU2

Resposta em IND, GDP e IBC

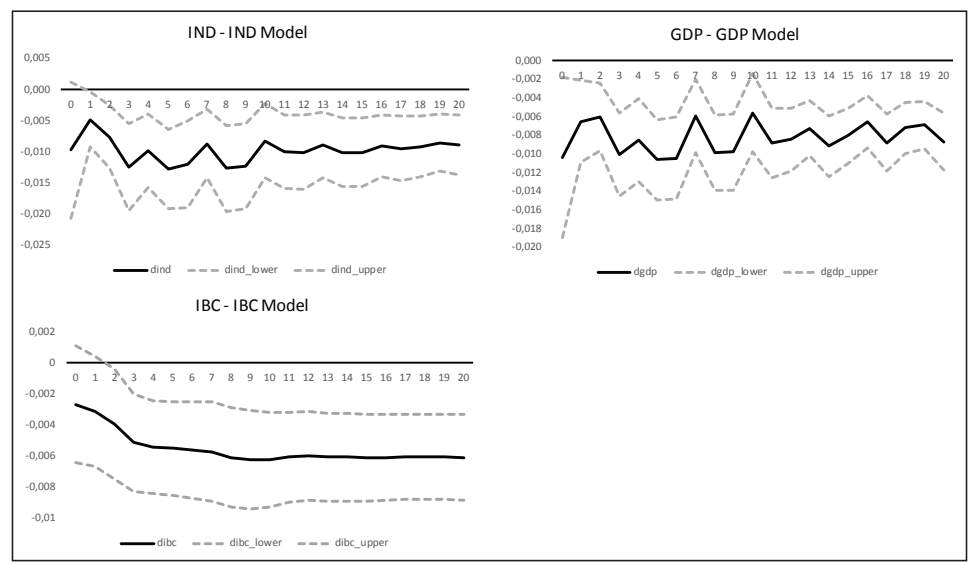

Fonte: Elaboração dos autores. Estatísticas estimadas pelo Software STATA 15.1.

No que tange ao efeito de DU2 sobre o nível de atividade, para o modelo VAR(IND-10), estima-se uma queda de $1,0 \%$, já no mês zero, onde se observa um comportamento cíclico na resposta em IND, atingindo o "vale" no $8^{\circ}$ mês, com um efeito acumulado de queda de $1,3 \%$. A partir do mês 10 tem-se que a IND passa a flutuar, em média, próximo de uma retração de $1,0 \%$. Esse efeito não se torna estatisticamente nulo em nenhum dos vinte meses estimados. A conclusão de que os efeitos do Regime de Baixa de CO, iniciado no final de 2014, sobre o nível de atividade da economia brasileira não são desprezíveis em todo o horizonte temporal estimado é corroborada nos modelos VAR(GDP-11) e VAR(IBC-6).

Os efeitos dos dois ciclos de baixa nas demais variáveis de interesse - inflação (IN), taxa de câmbio (EX) e os preços das commodities (CO) - estão reportados, respectivamente, nos Gráficos 3A e 4A, no Anexo. Com respeito ao primeiro ciclo, cabe destacar que não se observaram efeitos do choque negativo de $\mathrm{CO}$ sobre a inflação. Por outro lado, ainda que com diferenças marginais de intensidade e periodicidade nos três modelos estimados, foram observadas alterações estatisticamente significativas em EX, especialmente nos meses iniciais, cujo efeito máximo em termos de depreciação da moeda nacional foi de $6,6 \%$. A pressão sobre EX se extingue entre o $6^{\circ}$ e o $8^{\circ}$ mês a depender do modelo. Por fim, $\mathrm{CO}$ é negativamente atingido por choques na própria série nos três modelos. O segundo ciclo, mais longo, apresentou resultados diferentes, com destaque para o fato de que os três modelos apresentaram efeitos estatisticamente significativos na inflação, cujas máximas oscilaram entre $0,18 \%$ e $0,24 \%$; e os efeitos permanentes se aproximaram dos $0,20 \%$, em média, por volta de um ano a um ano de meio depois do choque. Com respeito à EX, também se percebe que, diferentemente do ciclo anterior, os efeitos são mais intensos e que esses não se dissipam. O pico de depreciação se aproximou dos $4 \%$, ao passo que a média esteve ao redor dos $2 \%$. Por sua vez, também nos três modelos se verificou efeito negativo de choques em CO na própria série. 
Dos resultados apontados até aqui, o mais relevante em termos do objetivo central deste trabalho é o de que os efeitos recessivos induzidos pelo choque negativo nos preços das commodities foram mais prolongados no período de $2014 \mathrm{e}$ 2016. Em todos os vinte meses do choque estimado, aqueles se revelaram como estatisticamente significativos nos três modelos. O mesmo não se observa no ciclo de baixa associado à CFG. Por conta disso, a Figura 5 estima as variações percentuais acumuladas e observadas nos indicadores de nível de atividade em (DU2). Inicia-se a comparação a partir da alteração de regime (07/2014), estendendo-se por vinte meses, como aplicado na função impulso-resposta (Figura 4). Na Figura 5 está especificada apenas a relação a partir do mês em que a queda observada (acumulada) torna-se negativa em todos os períodos seguintes.

Ao se considerar os três modelos, define-se um resultado mais consistente e permanente de queda no nível de atividade acumulado entre o $8^{\circ}$ e o $10^{\circ}$ mês após o impulso em DU2 ${ }^{13}$. Por consequência, nos primeiros meses do processo de retração da atividade econômica do Brasil o regime de baixa dos preços das commodities representou, em média, $1 / 3$ da queda - entre $26 \%$ e $37 \%$, dependendo do indicador de atividade econômica. Na medida em que se distancia do período de alteração do regime de alta para o de baixa em $\mathrm{CO}$, aquela contribuição se reduz para algo entre $8 \%$ e $13 \%$. Entretanto, o impacto negativo do choque nos preços das commodities não se dissipa ao longo do tempo, mesmo depois de emergirem outros prováveis choques contracionistas na atividade economia brasileira nos meses analisados, tais como: contração fiscal, elevação na taxa de juros, crise política, dentre outros.

Figura 5: Quedas Acumuladas no Nível de Atividade - Regime de Baixa 2014(7) até 2016(12) - DU2
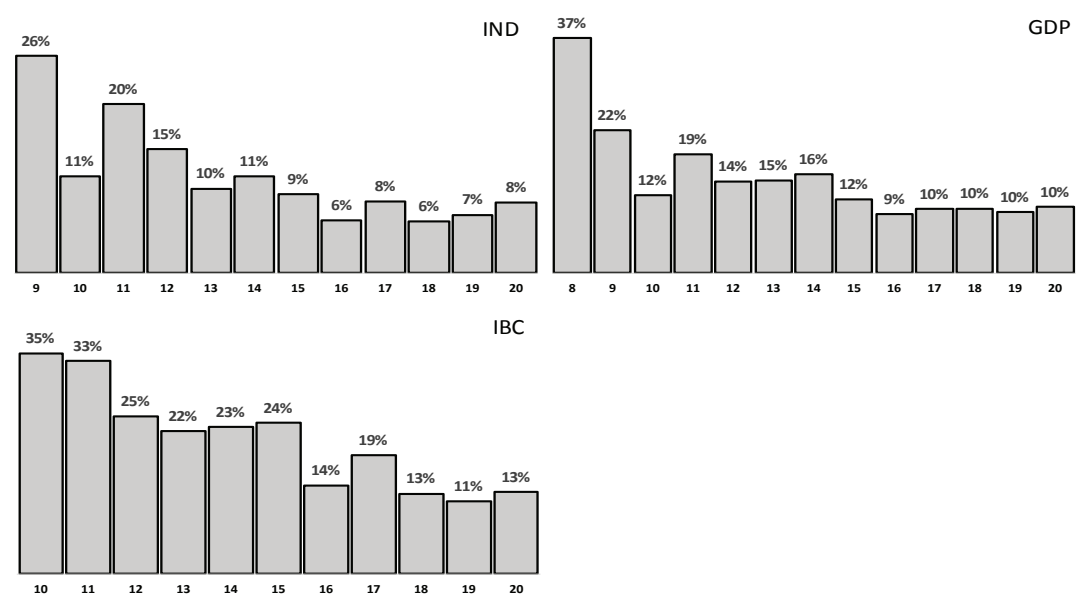

Fonte: Elaboração dos autores. Estatísticas estimadas pelo Software STATA 15.1.

\footnotetext{
${ }^{13}$ Antes desses meses tem-se um movimento de grande volatilidade na taxa de crescimento acumulada observada nos três indicadores de nível de atividade.
} 
Em síntese, é possível sugerir que os efeitos do Regime de Baixa dos $\mathrm{CO}$, que se inicia em 2014 (DU2), sobre as variáveis macroeconômicas selecionadas foram mais representativos e permanentes quando comparados com os efeitos do Regime de Baixa originário da CFG, a partir de 2008 (DU1). Tais resultados vão ao encontro da literatura recente que sugere ser desempenho macroeconômico dos países sul-americanos, em geral, e do Brasil, em particular, condicionado fortemente pelo choque dos termos de intercâmbio (De La Torre, 2016; Reinhart et al., 2016; Alberola-Ila, 2016). Nos anos 2000, isso se deu no contexto do que se convencionou chamar de superciclo de alta nos preços das commodities. Esse resultado reforça a perspectiva de que não se pode atribuir exclusivamente, ou mesmo, principalmente, a desaceleração econômica observada a partir do final de 2014, e que produziu uma profunda recessão, às escolhas de política doméstica.

Nossas estimativas sugerem que o efeito primário acumulado daqueles choques nas variações das três proxies utilizadas para capturar o nível de atividades do Brasil foi, em seu auge, de aproximadamente 1/3. Isso não considera outros efeitos externos, como os associados ao efeito do tapering ${ }^{14}$, a perda de vigor do comércio global, e o baixo crescimento dos principais parceiros comerciais do país, para citar alguns. Da mesma forma, não considera os demais efeitos domésticos que não os derivados de supostas decisões equivocadas de política econômica. Por decorrência, não se pode descartar a priori a hipótese de que os aspectos estruturais associados à especialização regressiva da economia brasileira e ao seu padrão de inserção internacional a tenham tornado mais vulnerável aos choques externos - financeiros e de preços das commodities. Tal perspectiva não encontra abrigo na literatura convencional, que, mesmo admitindo a existência de condicionantes externos, tende a apontar para o predomínio de fatores domésticos na desaceleração pós-2014. Assim, Borges (2016a, 2016b), Pessoa (2016) e Matos (2016) são exemplos do debate sobre os pesos relativos entre determinantes externos e internos, com os dois últimos pendendo para a ênfase nos aspectos idiossincráticos da gestão doméstica da política econômica.

\section{CONSIDERAÇÕES FINAIS}

O colapso no crescimento da economia brasileira desde o começo dos anos 1980 é tema recorrente na literatura. Há explicações divergentes para esse fenômeno, com as correntes interpretativas organizadas em torno de distintas matrizes teó-

\footnotetext{
${ }^{14}$ Esse se refere ao processo gradual de retirada dos estímulos monetários excepcionais do banco central dos Estados Unidos (FED), especialmente os associados ao afrouxamento quantitativo (AQ), política de compra mensal de títulos hipotecários e outros para aliviar os efeitos da crise subprime. O AQ vigorou entre dezembro de 2008 e dezembro 2013, porém, ainda no primeiro semestre de 2013, dirigentes do FED passaram a afirmar que a política seria encerrada, o que produziu uma forte reversão nos fluxos de capitais direcionados aos países emergentes (Unctad, 2016; BIS, 2018).
} 
ricas e ideológicas. Um argumento recorrente da perspectiva aqui chamada de convencional, e que reflete o mainstream da Economia, enfatiza as distorções de preços e de expectativas introduzidas pelo ativismo estatal. Alternativamente, autores institucionalistas, estruturalistas e keynesianos apontam para outra direção: enfatizam problemas associados aos padrões de inserção externa e de gestão macroeconômica e aos efeitos da especialização regressiva, vale dizer, a perda de diversidade e complexidade da estrutura produtiva e de comércio exterior.

Nos anos 2000, especialmente entre 2004 e 2010, e a despeito da eclosão da maior crise financeira internacional desde 1929, verificou-se um período de aceleração no ritmo de expansão da renda. Esse veio acompanhado de relativa estabilidade macroeconômica e de avanços sociais inequívocos. Na perspectiva convencional, tal resultado foi gerado pela combinação de "sorte" - o choque externo favorável nos termos de intercâmbio - e "continuísmo" - particularmente a manutenção do tripé de política macroeconômica herdado da gestão anterior. Todavia, segue a análise convencional, a retomada de intensa intervenção estatal na gestão Dilma Rousseff teria aprofundado os desequilíbrios fiscais, desorganizado setores econômicos, alterado preços relativos e desestabilizado as expectativas empresariais. Como resultado, emerge uma das maiores recessões do período republicano. Nota-se nessa linha de raciocínio que os choques externos de preços das commodities produziriam efeitos assimétricos: teriam forte poder explicativo na aceleração do PIB da gestão Luiz Inácio Lula da Silva, mas nenhuma relação estreita com a recessão da era Rousseff. Em contrapartida, sem negar os eventuais problemas de gestão macroeconômica, as críticas (e as explicações) alternativas procuram analisar os ciclos e o padrão de crescimento a partir da combinação de fatores estruturais e conjunturais, bem como consideram a existência (ou ausência) de componentes estratégicos e políticos derivados da adoção (ou não) de políticas de promoção do desenvolvimento.

No presente trabalho, assumiu-se, com base na literatura prévia, de inspiração estruturalista e kaldoriana (Palma, 2012; Bresser-Pereira et al., 2016; Ferrari Filho e Fonseca, 2015; Marconi et al., 2016; Hiratuka e Sarti, 2017; Fonseca et al., 2018), que a estrutura da economia brasileira tem-se alterado de forma radical e negativa, o que teria reduzido o seu potencial de crescimento e ampliado o grau de exposição aos ciclos financeiros e de preços de commodities. Em outras palavras, com a especialização regressiva das últimas décadas, em alguma medida o Brasil teria voltado à condição de economia "reflexa e dependente", para se tomar emprestada a expressão de Tavares (1972). Tendo esse pano de fundo, foram analisados os efeitos das mudanças nos regimes de preços das commodities sobre o nível de atividades, a taxa de câmbio e a inflação em dois momentos: na crise financeira global e depois de 2014. Ambos os períodos foram delimitados a partir de critérios estritamente estatísticos por meio da metodologia markoviana. Disso derivou-se a possibilidade de aplicação de modelos VAR para estimar os efeitos dinâmicos das mudanças nos regimes daqueles preços sobre as nossas variáveis de interesse. 
Como conclusões principais nossos exercícios permitem sugerir que: (i) a queda nos preços das commodities não produziu efeitos duradouros sobre as variáveis de nível de atividade e preços macroeconômicos no contexto da CFG; (ii) porém, no ciclo pós-2014 tais efeitos foram perenes no horizonte analisado; e (iii) em seu auge, 1/3 da contração do nível de atividades esteve associado à mudança no regime de preços das commodities. Tais resultados parecem estar relacionados a dois conjuntos de elementos, sendo que o primeiro se deve às características dos choques de baixa dos $\mathrm{CO}$; e o segundo está associado às características recentes da economia brasileira nos dois períodos delimitados (DU1 e DU2). O Regime de Baixa das commodities que se inicia em 2008 gerou uma retração mais acentuada no nível de atividades em comparação com os resultados iniciais do ciclo posterior DU2. Porém, como a sua duração foi mais curta, de sete meses, observou-se resultados cumulativos que não prosperaram. Vale dizer, estatisticamente os efeitos do primeiro choque não foram significativos para além de poucos meses. Já o Regime de Baixa que se inicia no final de 2014 caracterizou-se por uma duração de pelo menos 30 meses, já que persiste até a nossa última observação temporal, em dezembro de 2016. Com isso, os efeitos cumulativos sobre a retração no nível de atividades foram mais intensos e prolongados.

O segundo elemento nos remete aos graus de liberdade da condução política macroeconômica no Brasil no período do segundo Regime de Baixa dos CO (DU2) em um contexto marcado por pelo menos três aspectos estruturais: especialização regressiva da estrutura produtiva e de comércio exterior; elevada abertura financeira e grande exposição ao ambiente internacional ainda instável; e crise política que se agudiza. Por decorrência, diferentemente do ocorrido no ano de 2008, no final do ano 2014, e mais especificamente no início de 2015, tem-se uma situação de fragilidade maior no panorama conjuntural da economia brasileira. A inflação já sinalizava um movimento altista, as contas primárias do governo apresentavam resultados deficitários, porém, ainda pouco intensos ante os déficits posteriores, e o nível de atividade da economia já desacelerava desde o ano de 2013. Com isso, os efeitos oriundos da baixa dos preços das commodities podem ter sido amplificados, dificultando a capacidade de reação da economia brasileira ao choque negativo externo.

Tal interpretação não esgota o debate sobre o desempenho estrutural e conjuntural da economia brasileira. Ainda assim, foi sua pretensão contribuir com evidências adicionais pela combinação no uso de distintas metodologias econométricas. Até aqui, com nossos resultados e os de outros trabalhos, não se pode descartar a hipótese de que os choques externos afetaram a dinâmica macroeconômica doméstica no período analisado, o que pode revelar um aprofundamento das vulnerabilidades estruturais herdadas de um longo movimento de semiestagnação e de especialização regressiva. 


\section{REFERÊNCIAS BIBLIOGRÁFICAS}

Alberola-Ila, E. et al. (2016) "Output gaps and policy stabilisation in Latin America: the effect of commodity and capital flow cycles”. BIS Working Papers, n. 568, June. Basle, Bank for International Settlements, 2016.

Almeida Jr., M. F.; Lisboa, M. B.; Pessoa, S. (2015) “O ajuste inevitável”. Disponível em: https://mansueto.files.wordpress.com/2015/07/o-ajuste-inevitc3a1vel-vf_2.pdf, acesso em 05/06/2018.

Arestis, P.; Baltar, C. T.; Prates, D. M. (2017) The Brazilian Economy since the Great Financial Crisis of 2007/2008, Palgrave Macmillan.

Bacha, E. L., Bonelli, R. (2005) “Uma interpretação das causas da desaceleração econômica do Brasil”. Revista de Economia Política, $\mathrm{Vol} 25, \mathrm{n}^{\circ} 3$.

Bacha, E. L (org).(2016) A Crise Fiscal e Monetária Brasileira. Rio de Janeiro, Civilização Brasileira.

Barbosa Filho, F. H; Pessoa, S. (2014) "Desaceleração recente da economia”. In: Sob a Luz do Sol. São Paulo, SP: Insper/Centro de Debate de Políticas Públicas.

Barbosa Filho, N. (2015) “O desafio macroeconômico de 2015-2018”. Revista de Economia Política, vol. 35, n⿳3 3 (140), pp. 403-425.

Belluzzo, L. G. M.; Almeida, S. G. (2002) Depois da Queda - a Economia Brasileira da Crise da Dívida aos Impasses do Real. Rio de Janeiro: Civilização Brasileira.

BIS. (2018) "Globalisation and Deglobalisation”, BIS Papers n. 100, December. Basle, Bank for International Settlements.

Bonelli, R.; Veloso, F. (orgs.). (2016) A Crise de Crescimento do Brasil, Rio de Janeiro: Editora Elsevier.

Borges, B. $\left(2016^{\mathrm{a}}\right)$ "Bad Luck or Bad Policy: uma investigação das causas do baixo crescimento da economia brasileira nos últimos anos”. In: Bonelli, R.; Veloso, F. (orgs.) A Crise de Crescimento no Brasil. Rio de Janeiro: Elsevier.

Borges, B. (2016b) "Réplica ao comentário de Samuel Pessôa”. In: Bonelli, R..; Veloso, F. (orgs.). A Crise de Crescimento do Brasil, Rio de Janeiro: Editora Elsevier.

Bresser-Pereira, L. C. (2016) A Construção Política do Brasil: sociedade, economia e Estado desde a independência. São Paulo: Editora 34.

Bresser-Pereira, L. C., Nassif, A.; Feijó, C. (2016) “A reconstrução da indústria brasileira: a conexão entre o regime macroeconômico e a política industrial.” Revista de Economia Política, vol. 36, $\mathrm{n}^{\circ}$ 3 (144), pp. 493-513.

Cardoso, F. H. et al. (2018) Crise e Reinvenção da Política no Brasil. São Paulo, Cia das Letras.

Carrasco, V.; De Mello, J. M. P.; Duarte, I. (2014) “A Década Perdida: 2003 - 2012”. Texto para a Discussão No. 626, Departamento de Economia da PUC-Rio.

Carvalho, L. (2018) Valsa Brasileira: do boom ao caos econômico. São Paulo: Todavia.

Coutinho, L. (1997) "A especialização regressiva: um balanço do desempenho industrial pós-estabilização”. In: Velloso, J. P. R. (Coord.). Brasil: desafios de um país em transformação. Rio de Janeiro: José Olympio.

De La Torre, A. et al. (2016) The Commodity Cycle in Latin America: Mirages and Dilemmas. Washington, DC: World Bank.

Doornik, J. A. (2012) “A Markov-switching model with component structure for US GNP”. Economics Letters, v. 118, p. 265-268.

Doornik, J. A. (2013) Econometric Analysis with Markov-Switching Models - PcGiveTM 14 Vol V. 1 ed. London: Timberlake Consultants Ltd.

Enders, W. (2010) Applied Econometric Time Series. New Jersey: Wiley \& Sons, $3^{\text {rd }}$ ed.

Ferrari Filho, F.; Fonseca, P. C. D. (2015) "Which developmentalism? A Keynesian-Institutionalist Proposal". Review of Keynesian Economics, v. 3, issue 1, 90-107.

Fonseca, P. C. D. et al. (2018) Política econômica, instituições e classes sociais: os governos do partido dos trabalhadores no Brasil. Porto Alegre, RS: PPGE/UFRGS, 2018. Disponível em: http://professor.ufrgs.br/pedrofonseca/publications, acessão em 07/06/2018.

Franco, G. H. B. (2005) “Auge e declínio do inflacionismo no Brasil”. In: Giambiagi, F. et al (Org.). Economia brasileira contemporânea (1945-2004), 1ª edição. Rio de Janeiro: Campus Elsevier. 
Giambiagi, F. (2011) “Rompendo com a Ruptura: o Governo Lula (2003-2010)”. In: Giambiagi, F. et al. Economia Brasileira Contemporânea (1945-2010), 2a edição. Rio de Janeiro, Elsevier.

Giambiagi, F.; Almeida Jr., M. F. (2017) Retomada do Crescimento: diagnóstico e propostas. Rio de Janeiro, Elsevier.

Gobetti, S. W.; Orair, R. O. (2017) "Taxation and distribution of income in Brazil: new evidence from personal income tax data". Brazilian Journal of Political Economy, vol. 37, $\mathrm{n}^{\circ} 2$ (147), pp. 267-286.

Goldfeld, S. M.; Quandt, R. E. (1973) “A Markov model for switching regressions”. Journal of Econometrics, v. 1, p. 3-16.

Hamilton, J. D. (1989) "A new approach to the economic analysis of nonstationary time series and the business cycle.” Econometrica, v. 57, n. 2, p. 357-384.

Hamilton, J. D. (1994) Time Series Analysis. New Jersey: Princeton University Press.

Hiratuka, C.; Sarti, F. (2017) "Transformações na estrutura produtiva global, desindustrialização e desenvolvimento industrial no Brasil". Revista de Economia Política, v. 37, n.1 (146), p. 189-207.

IMF. (2018) World Economic Outlook (Database), April. Washington, DC: International Monetary Fund.

Juselius, K. (2006) The Cointegrated VAR Model: methodology and applications. New York: Oxford University Press.

Kim, Chang-Jin. (1994) “Dynamic linear models with Markov-switching”. Journal of Econometrics, v. 60 , p. $1-22$.

Lindgren, G. (1978) "Markov regime models for mixed distributions and switching regressions”. Scandinavian Journal of Statistics, v. 5, n. 2, p. 81-91.

Lisboa, M. B., Latif, Z. A. (2013) “Democracy and Growth in Brazil”. Insper Working Paper WPE: 311/2013. Disponível em: www.insper.edu.br/wp-content/.../2013_wpe311.pdf, acesso em 05/06/2018.

Lütkepohl, H. (2006) New Introduction to Multiple Time Series Analysis. Berlin: Springer.

Maddison, A. (2007) Contours of the World Economy 1-2030 AD: Essays in Macro-Economic History. Oxford: Oxford University Press.

Marconi, N.; Rocha, I. I.; Magacho, G. R. (2016) "Sectoral capabilities and productive structure: An input-output analysis of the key sectors of the Brazilian economy". Brazilian Journal of Political Economy, vol. 36, $\mathrm{n}^{\circ} 3$ (143), pp. 470-492.

Matos, S. (2016) “A desaceleração do crescimento brasileiro: causas externas ou domésticas?” In: Bonelli, R.; Veloso, F. (orgs.). A Crise de Crescimento do Brasil, Rio de Janeiro: Editora Elsevier.

Neri, M. (2011) A nova classe média: o lado brilhante da base da pirâmide. São Paulo: Saraiva.

Palma, J. G. (2012) “Was Brazil's recent growth acceleration the world's most overrated boom?”. Cambridge Working Papers in Economics, N. 1248. University of Cambridge.

Pereira, A. W.; Mattei, L. (Editors). (2016) The Brazilian Economy today: towards a new socio-economic model? New York: Palgrave Macmillan, $1^{\text {st }}$ edition.

Pessôa, S. (2016). Comentário ao texto "Bad luck or bad policy.”. In.: Bonelli, R.; Veloso, F. (orgs.). A Crise de Crescimento do Brasil, Rio de Janeiro: Editora Elsevier.

Prates, D. M. (2007) “A alta recente dos preços das commodities”. Revista de Economia Política, vol. $27, \mathrm{n}^{\circ} 3$ (107), pp. 323-344.

Reinhart, C. M.; Reinhart, V.; Trebesch, C. (2016) "Global cycles: capital flows, commodities, and sovereign defaults, 1815-2015”. American Economic Review, Papers \& Proceedings, 106(5): 574580 .

Singer, A. (2018) O Lulismo em Crise. São Paulo: Companhia das Letras.

Tavares. M. C. (1972) Da substituição de importações ao capitalismo financeiro. Rio de Janeiro: Zahar.

Unctad. (2016) Trade and Development Report 2016 - Structural transformation for inclusive and sustained growth. Geneva: UNCTAD.

Unido (2015). Industrial Development Report 2016. The Role of Technology and Innovation in Inclusive and Sustainable Industrial Development. Vienna: United Nations Industrial Development Organization. 


\section{ANEXO - TESTES E ESTATÍSTICAS DOS MODELOS APLICADOS}

Tabela 1: Estatísticas Estimadas para MScomp(2,2)-DR(p) dos Preços das Commodities - 1995(1) - 2016(12)

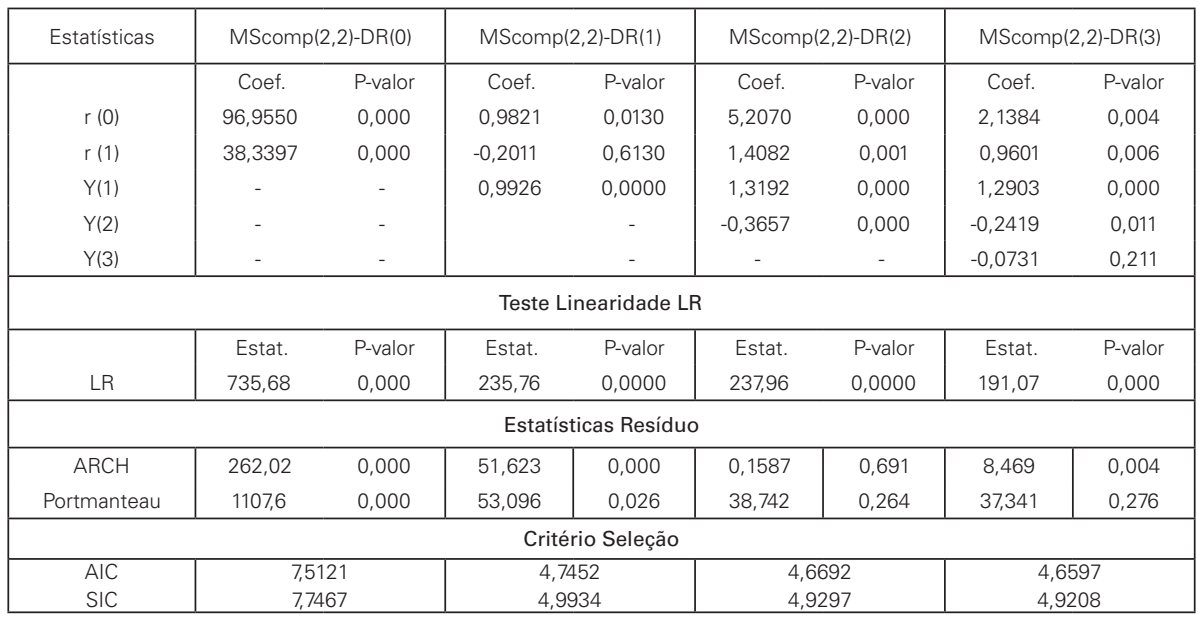

Fonte: Elaboração dos autores. Estatísticas estimadas pelo Software PcGive 14.

Tabela 2: Probabilidade de Transição para Média e para Variância no modelo MScomp(2,2)-DR(2) - 1995(1) — 2016(12)

\begin{tabular}{|c|ccc|cc|}
\hline \multicolumn{3}{|c}{ Média } & \multicolumn{2}{c|}{ Variância } \\
\hline & Regime 0,t & Regime 1,t & Regime 0,t & Regime 1,t \\
\hline Regime 0,t+1 & 0,97826 & 0,01375 & Regime 0,t+1 & 0,97826 & 0,01375 \\
Regime 1,t+1 & 0,02174 & 0,98625 & Regime 1,t+1 & 0,02174 & 0,98625 \\
\hline
\end{tabular}

Fonte: Elaboração dos autores. Estatísticas estimadas pelo Software PcGive 14.

Tabela 3: Periodicidade para os Regimes da Média e Variância no modelo MScomp(2,2)-DR(2) - 1995(1) - 2016(12)

\begin{tabular}{|c|ccc}
\hline \multicolumn{4}{|c}{ Média } \\
\hline & Inicio & Fim & $\begin{array}{c}\text { Duração } \\
\text { (mêses) }\end{array}$ \\
\hline \multirow{2}{*}{$\begin{array}{c}\text { Regime } \\
\text { Baixa }\end{array}$} & 1992(3) & $2005(5)$ & 159 \\
& $2008(8)$ & $2009(2)$ & 7 \\
\hline Regime & $2014(7)$ & $2016(12)$ & 30 \\
\hline Alta & $2009(3)$ & $2008(7)$ & 38 \\
\hline
\end{tabular}

\begin{tabular}{|c|c|c|c|}
\hline \multicolumn{4}{|c|}{ Variância } \\
\hline & Inicio & Fim & $\begin{array}{l}\text { Duração } \\
\text { (mêses) }\end{array}$ \\
\hline Regime & 1992(3) & 2000(3) & 97 \\
\hline Baixa & $2001(2)$ & $2002(10)$ & 21 \\
\hline Regime & 2000(4) & $2001(1)$ & 10 \\
\hline Alta & $2002(11)$ & $2016(12)$ & 170 \\
\hline
\end{tabular}

Fonte: Elaboração dos autores. Estatísticas estimadas pelo Software PcGive 14. 
Tabela 4: Estatísticas Estimadas para o

Modelo VAR-IND, VAR-GDP e VAR-IBC - 2002/01 até 2016/12:

\begin{tabular}{|c|c|c|c|c|c|c|c|c|c|c|}
\hline \multicolumn{11}{|c|}{ VAR - IND } \\
\hline Lags & 6 & & 7 & & 8 & & 9 & & 10 & \\
\hline & $\begin{array}{c}\text { AIC } \\
-21,3615\end{array}$ & $\begin{array}{c}\text { SIC } \\
-19,3930\end{array}$ & $\begin{array}{c}\text { AIC } \\
-21,2831\end{array}$ & $\begin{array}{c}\text { SIC } \\
-19,0139\end{array}$ & $\begin{array}{c}\text { AIC } \\
-21,23007\end{array}$ & $\begin{array}{c}\text { SIC } \\
-18,6579\end{array}$ & $\begin{array}{c}\text { AIC } \\
-21,2770\end{array}$ & $\begin{array}{c}\text { SIC } \\
-18,3994\end{array}$ & $\begin{array}{c}\text { AIC } \\
-21,2667\end{array}$ & $\begin{array}{c}\text { SIC } \\
-18,4924\end{array}$ \\
\hline \multicolumn{11}{|c|}{ Teste de Ruído Branco Portmanteau - Teste de Heterocedasticidade } \\
\hline & Chi-sq & p-valor & Chi-sq & p-valor & Chi-sq & p-valor & Chi-sq & p-valor & Chi-sq & p-valor \\
\hline IND & 11,1026 & 0,0254 & 12,4899 & 0,0856 & 14,3911 & 0,0446 & 15,0172 & 0,0905 & 13,0382 & 0,2215 \\
\hline IN & 0,8997 & 0,9246 & 1,2478 & 0,9898 & 0,6771 & 0,9985 & 1,3651 & 0,9980 & 12,2798 & 0,2668 \\
\hline EX & 25,4155 & 0,0000 & 23,9004 & 0,0012 & 17,0132 & 0,0173 & 11,2779 & 0,2571 & 18,2243 & 0,0513 \\
\hline $\mathrm{CO}$ & 2,0424 & 0,7280 & 2,0739 & 0,9556 & 2,203 & 0,9478 & 5,5753 & 0,7816 & 6,7541 & 0,7484 \\
\hline \multicolumn{11}{|c|}{ Teste LM - Teste Autocorrelação } \\
\hline Lags & LM & $\mathrm{p}$-valor & LM & p-valor & LM & p-valor & LM & $\mathrm{p}$-valor & LM & $\mathrm{p}$-valor \\
\hline 1 & 17,6130 & 0,3470 & 16,1574 & 0,44203 & 24,8227 & 0,07301 & 72,8799 & 0,0000 & 14,2305 & 0,58155 \\
\hline 2 & 15,7763 & 0,4687 & 18,1977 & 0,31245 & 46,225 & 0,00009 & 46,0533 & 0,0001 & 25,7253 & 0,05802 \\
\hline \multicolumn{11}{|c|}{ VAR - GDP } \\
\hline Lags & 7 & & 8 & & 9 & & 10 & & 11 & \\
\hline & $\mathrm{AIC}$ & $\mathrm{SIC}$ & $\mathrm{AIC}$ & $\mathrm{SIC}$ & $\mathrm{AIC}$ & $\mathrm{SIC}$ & $\mathrm{AIC}$ & $\mathrm{SIC}$ & $\mathrm{AIC}$ & $\mathrm{SIC}$ \\
\hline & $-21,9711$ & $-19,7020$ & $-21,9321$ & $-19,3600$ & $-21,9470$ & $-19,0694$ & $-22,3663$ & $-19,1809$ & $-22,4825$ & $-18,9866$ \\
\hline \multicolumn{11}{|c|}{ Teste de Ruído Branco Portmanteau - Teste de Heterocedasticidade } \\
\hline & Chi-sq & p-valor & Chi-sq & p-valor & Chi-sq & p-valor & Chi-sq & p-valor & Chi-sq & p-valor \\
\hline GDP & 9,0006 & 0,2526 & 10,2646 & 0,2469 & 8,8446 & 0,4517 & 14,5508 & 0,1493 & 16,5218 & 0,1228 \\
\hline IN & 1,0968 & 0,9931 & 0,3133 & 1,0000 & 0,4149 & 1,0000 & 11,5050 & 0,3195 & 17,0530 & 0,1063 \\
\hline EX & 27,0378 & 0,0003 & 22,6388 & 0,0039 & 14,3979 & 0,1089 & 23,3186 & 0,0096 & 17,2306 & 0,1012 \\
\hline $\mathrm{CO}$ & 3,9465 & 0,7859 & 3,2954 & 0,9145 & 5,7424 & 0,7654 & 6,2834 & 0,7909 & 5,2233 & 0,9199 \\
\hline \multicolumn{11}{|c|}{ Teste LM - Teste Autocorrelação } \\
\hline Lags & LM & p-valor & LM & p-valor & LM & p-valor & LM & p-valor & LM & p-valor \\
\hline 1 & 9,6475 & 0,8843 & 22,6156 & 0,1244 & 74,7548 & 0,0000 & 21,7212 & 0,1524 & 21,1938 & 0,1711 \\
\hline 2 & 21,1771 & 0,1718 & 57,8625 & 0,0000 & 53,6474 & 0,0001 & 30,6620 & 0,0148 & 23,4283 & 0,1027 \\
\hline \multicolumn{11}{|c|}{ VAR - IBC } \\
\hline Lags & 2 & & 3 & & 4 & & 5 & & 6 & \\
\hline & $\mathrm{AlC}$ & $\mathrm{SIC}$ & $\mathrm{AlC}$ & $\mathrm{SIC}$ & AIC & $\mathrm{SIC}$ & $\mathrm{AIC}$ & $\mathrm{SIC}$ & $\mathrm{AIC}$ & $\mathrm{SIC}$ \\
\hline & $-24,4208$ & $-23,5926$ & $-24,4158$ & $-23,2817$ & $-24,3983$ & $-22,9559$ & $-24,3838$ & $-22,6304$ & $-24,2782$ & $-22,2112$ \\
\hline \multicolumn{11}{|c|}{ Teste de Ruído Branco Portmanteau - Teste de Heterocedasticidade } \\
\hline & Chi-sq & p-valor & Chi-sq & p-valor & Chi-sq & p-valor & Chi-sq & p-valor & Chi-sq & p-valor \\
\hline IBC & 11,8449 & 0,0027 & 19,4600 & 0,0002 & 12,4892 & 0,0141 & 9,6962 & 0,0843 & 12,3868 & 0,0539 \\
\hline IN & 10,6712 & 0,0048 & 11,8782 & 0,0078 & 24,7831 & 0,0001 & 15,2278 & 0,0094 & 11,1380 & 0,0842 \\
\hline EX & 17,2635 & 0,0002 & 12,0935 & 0,0071 & 8,5799 & 0,0725 & 8,3291 & 0,1390 & 10,5905 & 0,1019 \\
\hline $\mathrm{CO}$ & 1,2202 & 0,5433 & 1,4303 & 0,6985 & 3,1164 & 0,5385 & 2,5378 & 0,7708 & 2,7049 & 0,8449 \\
\hline \multicolumn{11}{|c|}{ Teste LM - Teste Autocorrelação } \\
\hline Lags & LM & $\mathrm{p}$-valor & LM & $\mathrm{p}$-valor & LM & p-valor & LM & $p$-valor & LM & p-valor \\
\hline 1 & 25,0143 & 0,0695 & 16,8531 & 0,3952 & 16,0652 & 0,4484 & 15,4605 & 0,4921 & 20,7432 & 0,1885 \\
\hline 2 & 22,6385 & 0,1237 & 36,4280 & 0,0025 & 23,8620 & 0,0925 & 19,5141 & 0,2429 & 18,4167 & 0,3001 \\
\hline
\end{tabular}

Fonte: Elaboração dos autores. Estatísticas estimadas pelo Software STATA 15.1.

Tabela 5: Teste de Raiz Unitária nas Séries dos Modelo Estimados - 2002(1) - 2016(12)

\begin{tabular}{|c|c|c|c|c|c|c|c|c|c|c|c|}
\hline & IND (3 lags) & & GDP (3 lag) & & IBC (2 lags) & & EX (1) la & & IN $(1$ lags & & $\mathrm{CO}(1 \mathrm{lag})$ \\
\hline ADF -Estatística & $-1,687$ & $I(1)$ & $-1,218$ & I(1) & $-1,856$ & I(1) & $-1,266$ & $I(1)$ & $-3,226$ & I(1) & $-2,254$ \\
\hline \multirow[t]{2}{*}{ ADF - Critco - Significância 5\% } & $-2,878$ & & $-2,878$ & & $-2,878$ & & $-2,878$ & & $-3,435$ & & $-2,878$ \\
\hline & IND (trend) & & GDP (trend) & & IBC (trend) & & EX & & IN (trend) & & $\mathrm{CO}$ (trend) \\
\hline KPSS - Estatística & 0,339 & $I(1)$ & 0,233 & I(1) & 0,307 & I(1) & 0,376 & $I(0)$ & 0,179 & I(1) & 0,335 \\
\hline \multirow[t]{2}{*}{ KPSS - Critico - significância 5\% } & 0,146 & & 0,146 & & 0,146 & & 0,463 & & 0,146 & & 0,146 \\
\hline & EA (1 lag) & & GDP (1 lag) & & IBC (2 lags) & & EX (1 la & & IN (1 lag) & & $\mathrm{CO}$ (1 lag) \\
\hline ADF Break - Estatística & $-2,730$ & $I(1)$ & $-2,968$ & $I(1)$ & $-2,917$ & I(1) & $-2,243$ & $I(1)$ & $-2,897$ & $I(1)$ & $-2,739$ \\
\hline \multirow[t]{2}{*}{ ADF Break - Critico - Significância 5\% } & $-4,444$ & & $-4,444$ & & $-4,444$ & & $-4,444$ & & $-4,444$ & & $-4,444$ \\
\hline & EA (3 lag) & & GDP (3 lag) & & IBC (2 lags) & & EX (1 la & & IN (3 lag) & & $\mathrm{CO}$ (1 lag) \\
\hline ZA -Estatística & $-3,148$ & $I(1)$ & $-2,867$ & I(1) & $-2,260$ & I(1) & $-2,782$ & $I(1)$ & $-5,062$ & $I(0)$ & $-3,473$ \\
\hline ZA - Critico - Significância 5\% & $-4,8$ & & $-4,80$ & & $-4,80$ & & $-4,80$ & & $-4,80$ & & $-4,80$ \\
\hline
\end{tabular}

Fonte: Elaboração dos autores. Estatísticas estimadas pelo Software STATA 15.1. 